\title{
A study of the environmental culture of students of technical universities
}

\author{
U.Sh. Kholboeva, M.S.Ostapenko \\ Industrial University of Tyumen, Tyumen, Russia
}

\begin{abstract}
Environmental culture is the main factor in the organization of an environmentally oriented specialist. It is the environmental culture and consciousness of the specialist that is the key to their practical readiness to treat the environment responsibly and take enviro-oriented decisions using the received knowledge. Consequently, the matter of the development of environmental culture of the student is a relevant research topic. Students, who are future professionals, must clearly understand the level of their impact on the environment, have proficient knowledge in the field of environmental science, and use it as a basis for decision-making. For that purpose, we conducted research on the environmental culture of the students of technical faculties. According to the received data, we identified several problems. Supported by the earlier research of scientists in this sphere and personal opinion of the authors, we proposed practical methods of raising the students' environmental culture which can add to the existing knowledge in this sphere. The results of the research are presented in this paper.
\end{abstract}

\section{Introduction}

Books dealing with environmental aspects have mainly studied the human impact on the environment from a technological and economic point of view. Thus, the greatest amount of research was devoted to the reduction of emissions into the environment, as well as increasing the encl effect through the implementation of environmental practices in the industry. They focused on the introduction of green corps in industry [1], sustainability management in an industrial enterprise [2], reducing carbon dioxide emissions using the environmental chain project [3], and the introduction of environmental education [4]. But during the study of these factors, they did not pay sufficient attention to cultural aspects. It is culture that is a factor in the formation of man, it determines the level of development of the inner world, as well as actions based on certain worldviews. Rapoport [5] defines culture as a total of three positions that complement each other and express the culture concept. The first position expresses culture as a way of life of a particular group of people. The second one defines it as a system of symbols and cognitive schemes conveyed as through symbolical codes. The third one defines it as a set of adaptive strategies of survival related to ecology and resource consumption. Therefore, Linton [6] understands culture as a scope of knowledge, sets, and habitual models of behaviors that are transmitted through members of a particular group of people. 
Consequently, culture is the rate of human activity that has an influences the actions of men for their benefit or in the interest of others. Consequently, we can conclude that culture develops in an endogenous way and depends not only on external facts but also on the inner world of man. This paper studies the type of culture that organizes human attitudes and relationships leading to the development of solicitous attitude to the environment in the context of conscious consumption. This type is called "ecological culture," and the development of this type determines the state of ecology in several decades ahead.

Gagarin's research noted the importance of developing an ecological culture development and education of environmentally-oriented character. He positions an environmentally-oriented worldview as an ideal ("topmost") quality of human being, which determines its place as a subject in developing space (natural and social) of life. [7]. In his papers, Fokin state that the most critical component of the environmentally oriented worldview is such life values and principles, which are based on the inherent nature of the environment and the planet as a whole and on the certainty of a person that he/she is responsible for their preservation (i.e., environmentally-oriented) through his/her rationality. Besides, it also includes ways of perception of the external natural world, norms of ecological behavior and personal (subjective) attitude to it, motivational consumption sphere and, as a result, the individuality of the person as a subject of the worldview [8].

The chapter "Survey results" of this paper presents, the results of a survey conducted among students of different technical faculties and the problems identified. The survey revealed that the development of environmental culture of the respondents is endogenous in nature and often depends on the personal motivation of the individual. Also, the survey determined that the level of the respondent's readiness to give up personal achievement for the sake of saving nature is formed with ageing and depends not only on internal motives but also on the well-being of the respondent. i.e., we can think that a person's age and experience play a significant role in the formation of the environmentally oriented worldview.

In the chapter "Theoretical and practical solutions to the problems of students' environmental culture development" theoretical and practical methods of introducing environmentally-oriented education taking into account the state of respondents' environmental culture are proposed. Considering that the development of environmental culture is endogenous in nature, the proposed methods form a gradual interest in environmental preservation and gradually motivate the student to move from one to another. Thus, the application of these methods can promote practical usage and further development of environmental culture. In the last chapter, we studied the personal motivation of students in the development of the environmental culture and prospects for further study of this issue as one of the essential stimuli for the formation of not only environmentally-oriented human worldview, but also as a major factor in training of an environmentally-oriented specialist, ready to take both practical and theoretical decisions about environmental conservation.

\section{$2 \quad$ Materials and methods}

\subsection{Participants}

Participants for the study were selected using the cluster sampling method. For this purpose, the respondents selected were mainly studying in technical areas. In addition to technical students, the sample included students from the department of humanities and natural sciences. Since the emphasis was placed on students from technical universities, there were few respondents from other areas. This did not allow us to consider the 
development of the environmental culture of students in the humanities more deeply and compare them with respondents from technical areas. The study participants were selected randomly, without any specific criteria. Thanks to this, we were able to research the environmental culture of students from different backgrounds, with different status and attitudes to environmental science. This study involved 206 females and 201 males. They were in-formed about their participation via e-mail or a personal message on social networks. They were provided with a range of questions aimed at studying the state of environmental culture during their studies at the university. The research was conducted from 10.02.2020 to 10.03.2020, and the results are based only on the responses of respondents and their attitudes to the environment.

\subsection{Data gathering methods}

The method of data gathering was an anonymous survey of respondents. This method was the most effective at the beginning of the pandemic and allowed us to identify the closest responses to reality. Thanks to anonymity, respondents could answer the questions asked honestly, without concerns of being declawed. The method of the anonymous survey in electronic form allowed to get answers from a large number of respondents. This helped to get results that were as close as possible to the true values. Unfortunately, the disadvantage of the anonymous survey was that the respondents chose one of the submitted answers that are closest to their position. Therefore, it is impossible to judge the accuracy of these estimates. The method of sampling respondents was used randomly and did not depend on any specific characteristics. This method allowed the authors to expand the range of respondents and get more answers. Respondents were provided with a questionnaire divided into three blocks of questions, set in a certain order. The first set of questions included general questions asking respondents about their grade, gender, and area of study. In the second block questions aimed at identifying the respondent's attitude to the environment and environ-mental problems. The third block included questions aimed at identifying the environmental culture of students and their knowledge on this topic. The final questions of the study were: "Do you think it is necessary to develop an environmental culture among students?" and " It is necessary to pay attention to environmental issues in the learning process?" These questions were necessary for further explore the topic of teaching environmental culture to students.

\subsection{Procedure}

The survey procedure was conducted by means of an Internet questionnaire of a random sample of technical university students. The anonymous survey consisted of 15 multiplechoice questions. The respondents took about 6-8 minutes to answer the questions. Before the survey, respondents were provided with information about the survey goals and the further use of their responses. They were also told that the anonymity of their responses would be preserved and the results would be used for research purposes only.

\section{$3 \quad$ Results}

The conducted survey was a practical method of obtaining data on the state of students' environmental culture, as the method of anonymous survey allows respondents to express their opinion in the freeway, without the fear of criticism from the researcher. Thus, during the study, 407 respondents from different training programs and courses expressed their opinions. Two hundred six women and 201 men of 1-st up to 5-th grades took part in the survey. Data on the grades of female and male students are presented in Figure 1. The 
Figure shows that the number of participants of the second grade prevails over others. Then go the first, second, fourth, and fifth-year students.

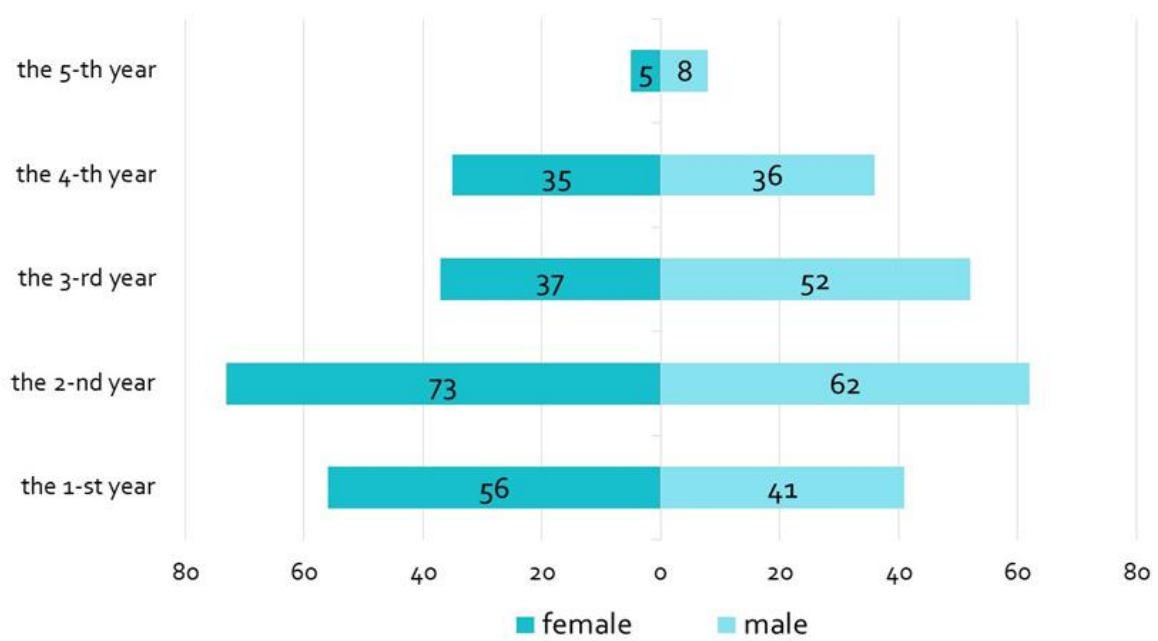

Fig 1. The balance between female and male students by the years of study.

Such gradation of the participants makes it possible to see a more thorough development of the environmental culture of students of different years of study. Each respondent was allowed to answer several questions about the environmental situation and his/her attitude to this matter. There were loaded questions that showed the respondents' readiness to take part in the sphere of environmentalization and also expressed their attitudes to the environment.

One of the first questions asked to our respondents was the question about responsibility for the environment of the region, and, to be more precise, who must take responsibility for the environmental conditions in the region. The data is presented in Figure 2 (in the form of the number of respondents).

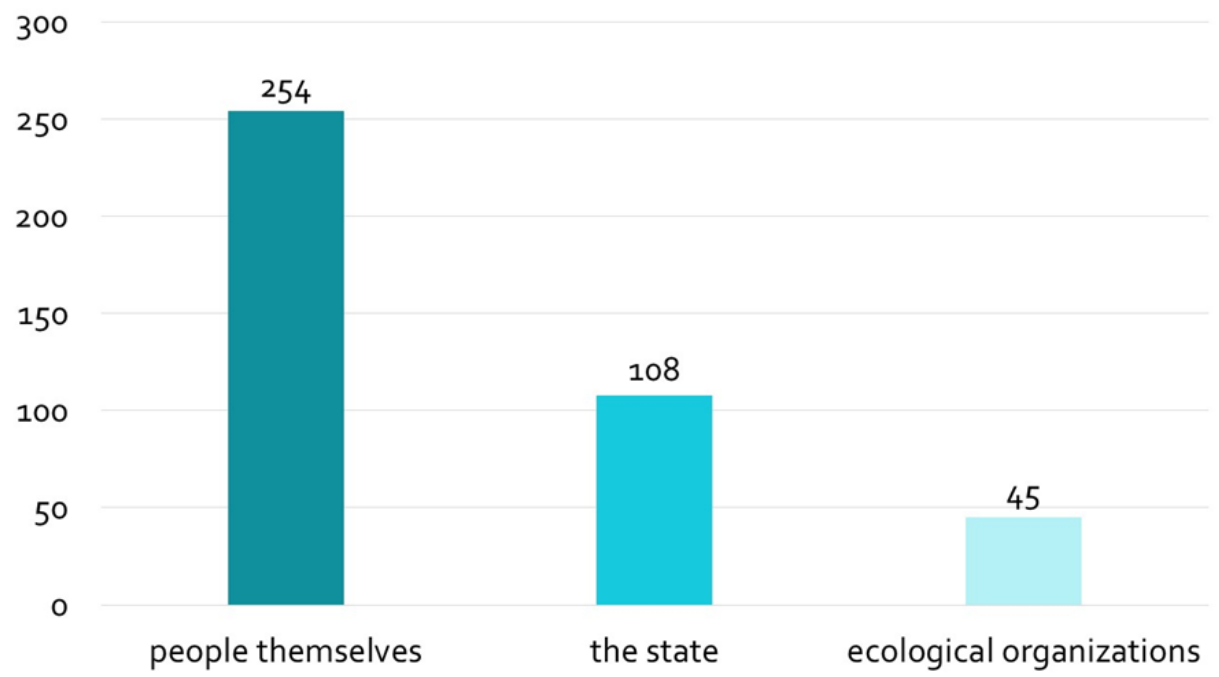

Fig. 2. Division of responsibility among respondents. 
Figure 2 shows that most of the respondents are ready to take responsibility for the environmental conditions in the region where they live. That is $62 \%$ of the respondents. However, not all of the respondents are ready to take responsibility for their region's environmental conditions; $27 \%$ of the respondents think that the state must take this responsibility and $11 \%$ of the respondents confer responsibility on environmental organizations.

In order to study the level of responsibility more thoroughly, the respondents were divided based on their sex and the year of study. Thus, the authors managed to study the conditions of assuming environmental responsibility among female and male students of different years of studying.

First, let us examine the level of responsibility among the female students of various years of study. The scheme of division is presented in Figure 3.

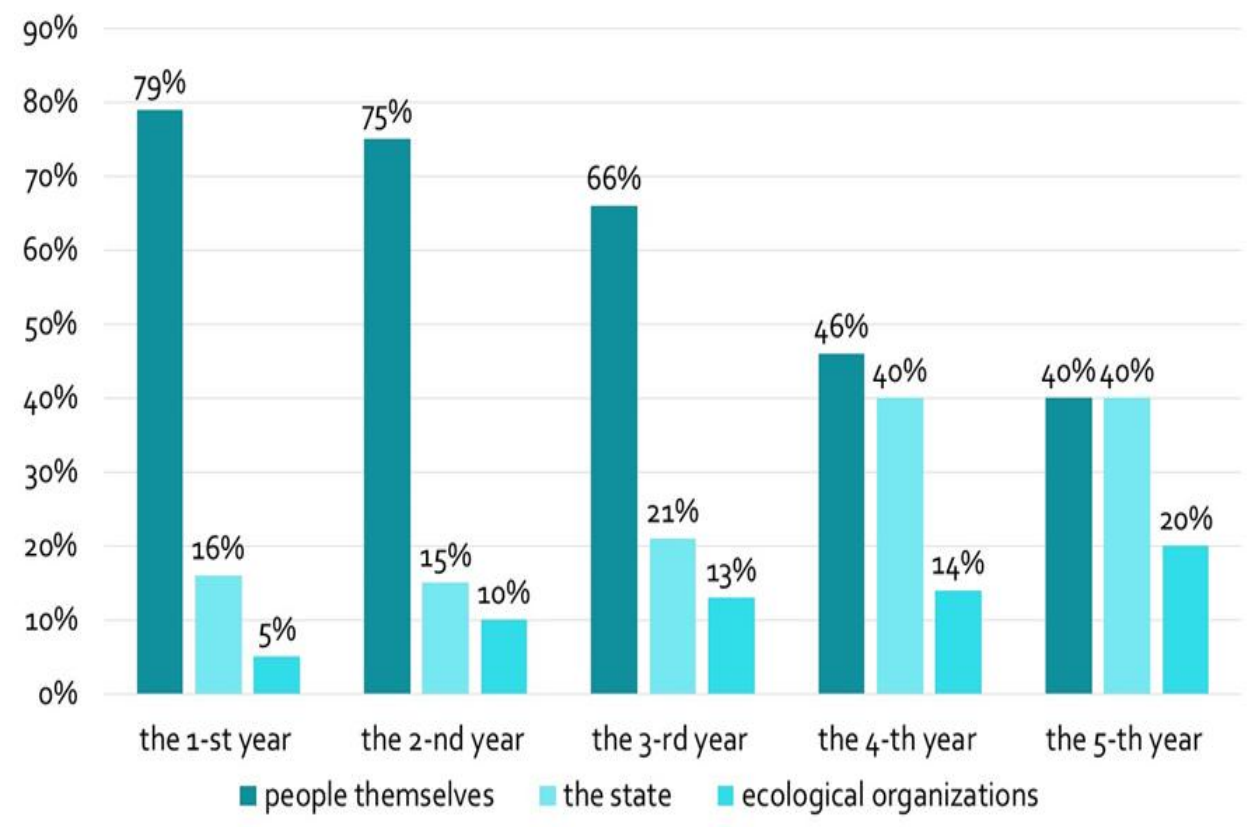

Fig. 3. The division of responsibility among the female respondents.

We can see from the diagram that first-year students are more inclined to take responsibility on their own. If $79 \%$ of the first-year students think that people should take responsibility for the region's environmental situation, then only $40 \%$ of the fifth-year students agree with this opinion. Such dynamics is very harmful because last-year students are specialists who will face problems connected with the environment, and the level of the environmental welfare of the region where they work will depend on the grade of the environmental orientation of their decisions. Also, this balance shows that with each new study year female students delegate the responsibility concerning the environmental welfare to the state and also to environmental organizations. Further, let us study the same rate among male students. The division diagram is presented in Figure 4. 


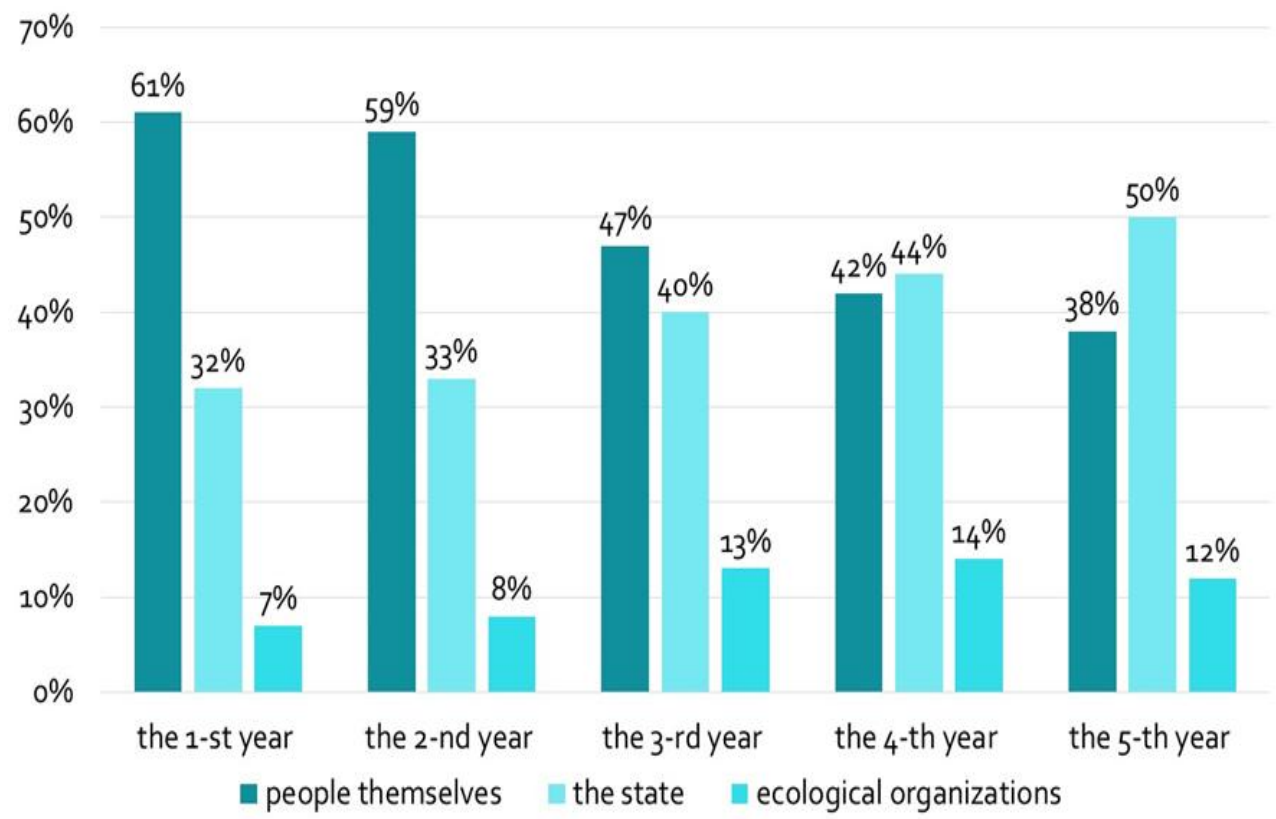

Fig. 4. Division of the responsibility among the male respondents.

As we can see from the diagram, the dynamics of the responsibility level is close to the females' one, but the males' drop is more significant. Thus, if we compare the percentage of students who hold the state accountable among the first-year students, the percentage of women is $16 \%$, and the percentage of men is twice high, $32 \%$.

The situation with the assignment of responsibility is the same as among women, with an increase in percentage: the rate of responsibility assignment to the state and environmental organizations increases and the level of personal responsibility decreases.

Can we talk in such a situation about the unevenness of the environmental culture among students? Maybe it is too early to talk about that without examining all percentages studied in the survey.

The next question the respondents were asked was if they would like to take part in environmental -political decisions in case they had such an opportunity? To get a detailed Figure of the division between women and men, we divided them according to gender and the year of study. Thus, we received the following results.

In Figure 5 we can see the extent to which female representatives are ready to take part in environmental political decisions. On the diagram, we can see that the dynamics of the decision making is unstable and depends on their attitude to environmental legislation.: 


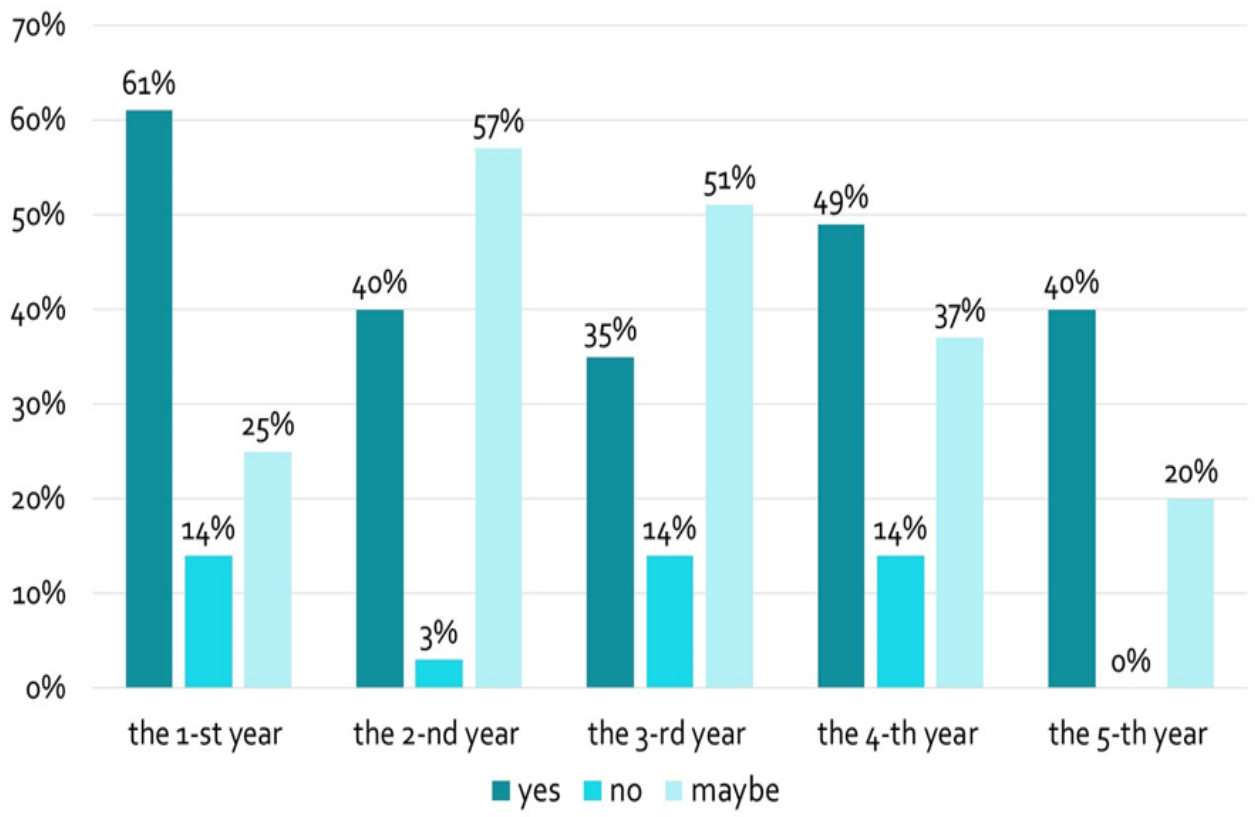

Fig. 5. Readiness to take part in taking environmental political decisions among female respondents.

In this scheme, it is impossible to make a clear formulation of the law of development of female respondents' wishes, but we need to pay attention to the results of the female students of the 5-th school year. The diagram shows that there are no damaging answers to this question. Thus, we can assume that with the increase of knowledge and experience, female respondents are inclined to take part in the environmentalization process and life in general. It is worth mentioning that female respondents' confidence in their answers decreases as the school year increases The answer "maybe" prevails over the affirmative "yes".

Further, we studied the results of the male students of different school years, who also chose between variants "yes", "no" and "may-be". The diagram of the answer division is shown in Figure 6. 


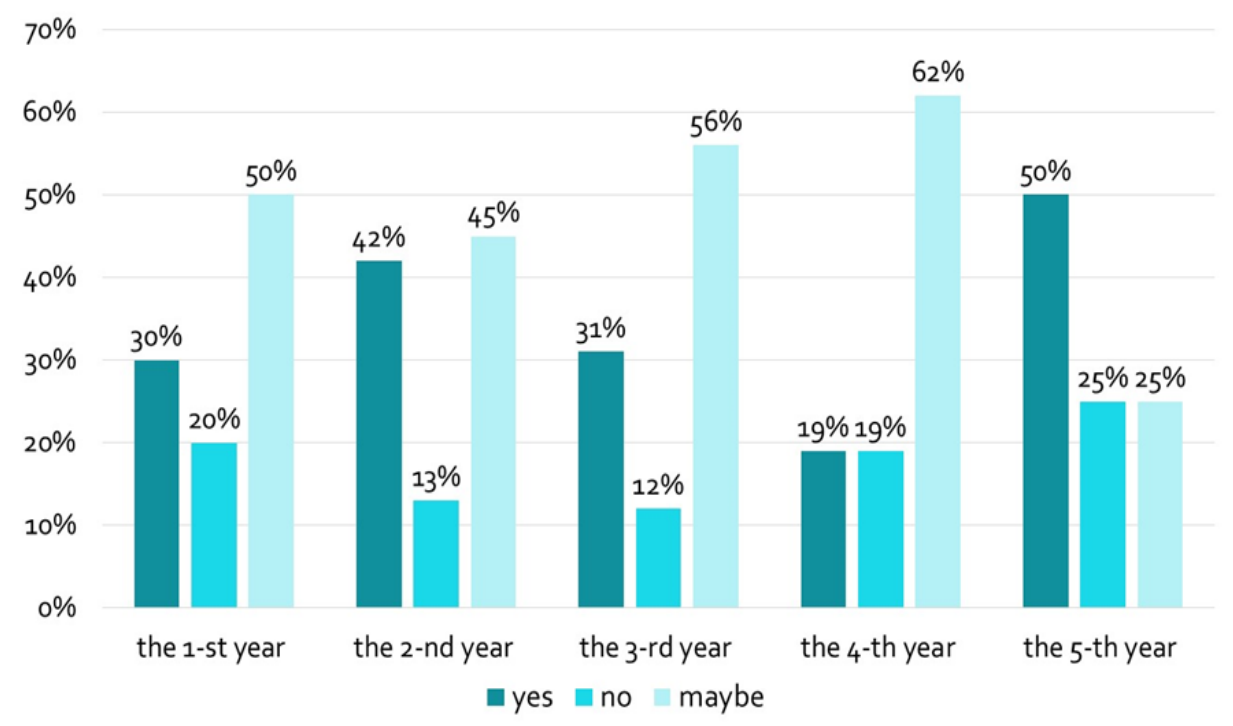

Fig 6. Readiness to take part in ecological-political decisions among the male respondents.

Here again there is an unstable division of results between respondents, but it is worth mentioning that the percentage of men who gave a negative answer prevails over women. For example, the proportion of women who answered affirmatively to this question was $61 \%$ among first-year students, compared with $30 \%$ among men.

The next question our respondents were asked was about whether they could refuse to increase their personal wealth if it was necessary for the preservation of the environment? This question shows to what extent respondents are willing to give up financial gain for the sake of preserving the environment. Most European countries have, a system of "green taxes" based on the "polluter pays" principle, i.e., every citizen pays appropriate taxes for the impact of one degree or another on the environment. This way can have a positive impact on the human ability to appreciate natural resources and use them more efficiently. Again, we divided them by gender and the study year to determine the willingness of respondents. 


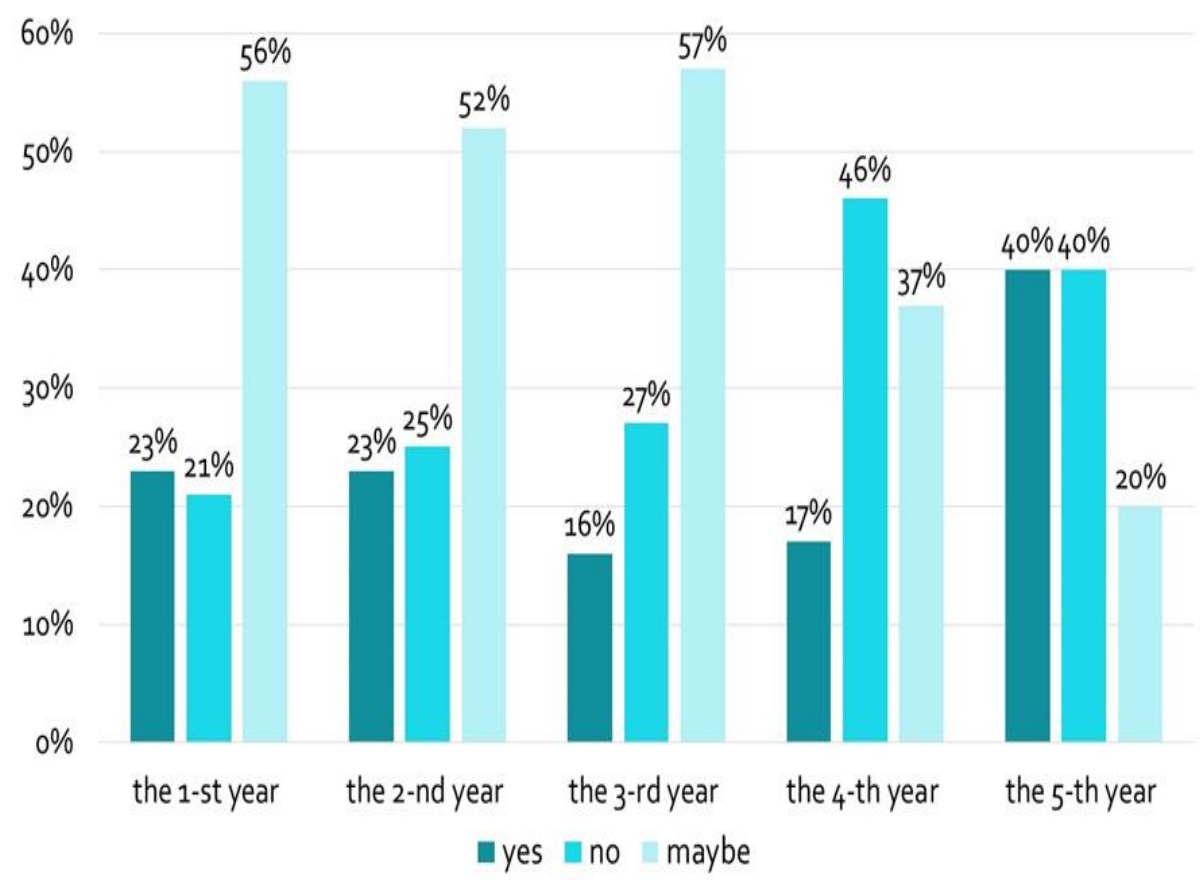

Fig. 7. Readiness to refuse from a small percent of financial welfare among the female respondents.

The answers in this diagram are quite inconsistent again, and we can say that the level of readiness to give up well-being depends on the state of the respondents' environmental culture, as well as on the existing knowledge base acquired during their studies. As noted earlier, environmental culture is a set of internal and external factors that influence a person's worldview, and it also includes the inner motivation of the person. This Figure shows that in many cases, the negative response prevails over the affirmative indicating that "the polluter" is not ready to take responsibility for the environment. It is possible to reach improvement of the environmental situation using economic consciousness and education.

Similarly, we plotted the breakdown of male respondents' answers and divided them by year of the study. The results are presented in Figure 8. 


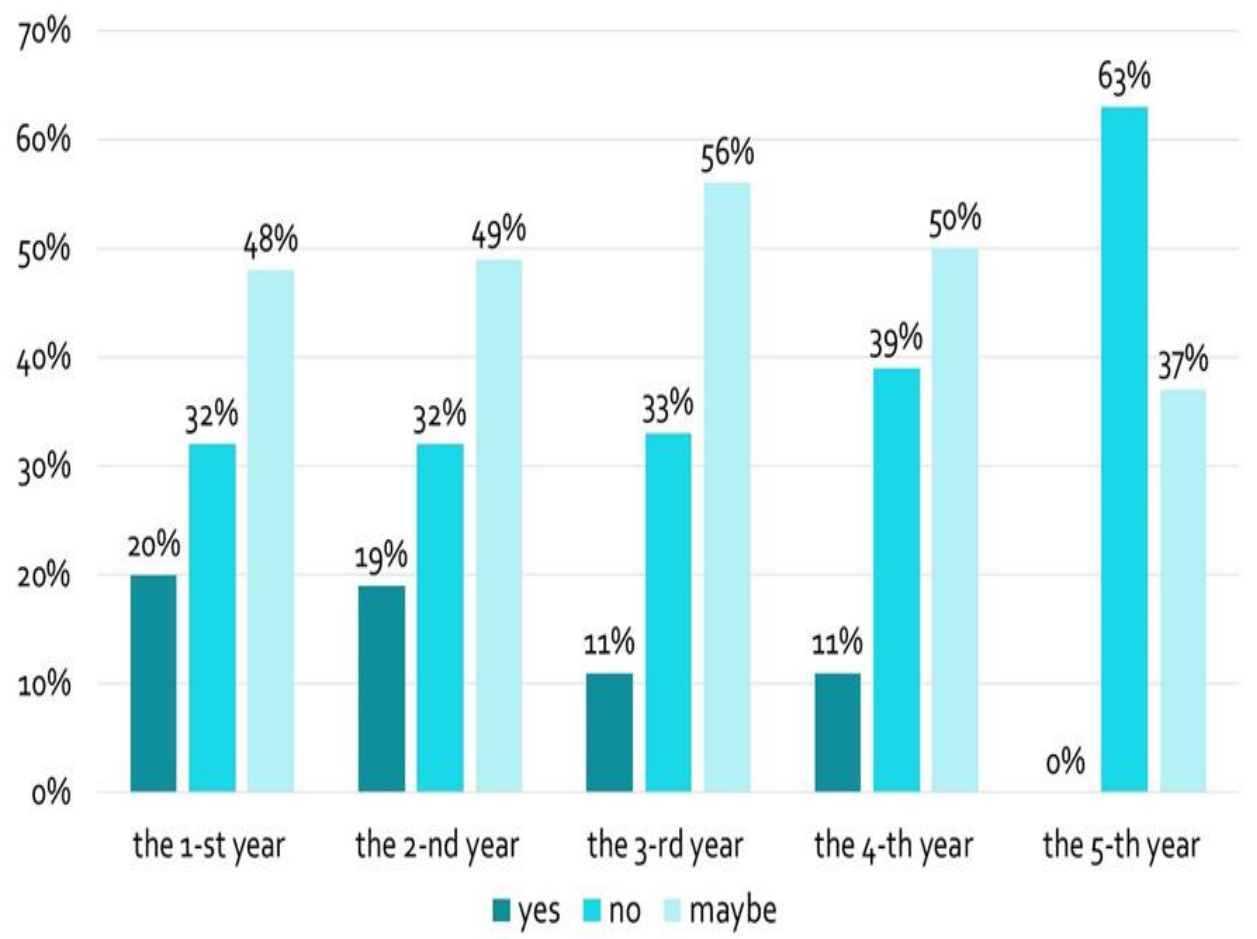

Fig. 8. Readiness to refuse a small percent of financial welfare among male respondents.

This diagram more clearly shows the attitudes of male representatives towards the abandonment of well-being in order to preserve environmental well-being. This parameter decreases as the age of the respondent increases. For example, $20 \%$ of the first-year respondents agreed to give up a small per centage of financial well-being in order to save the environment; then, up to the fifth year of study, no one answered in the affirmative. The diagram also shows an increase in the number of negative responses to this question along with an increase in the school year. It suggests that with the environmental orientation of the male representative's decreases with age, which may impact the environmentallyoriented decision-makings of the future professional.

Also during the survey, the respondents answered the questioned mentioned to determine the attitude of the consumer to nature. It consisted of a choice of the respondents of the level of necessity of nature in their life. Answering the question "what is natural for you," most of the respondents said that it a state of good leisure, but it is worth mentioning that only $20 \%$ of 407 respondents include nature in the list of their interests. It tells us that the consumerist attitude toward nature and its resources prevails among respondents of all ages and genders studied. The diagram of division of answers to this question is presented in Figure 9. 


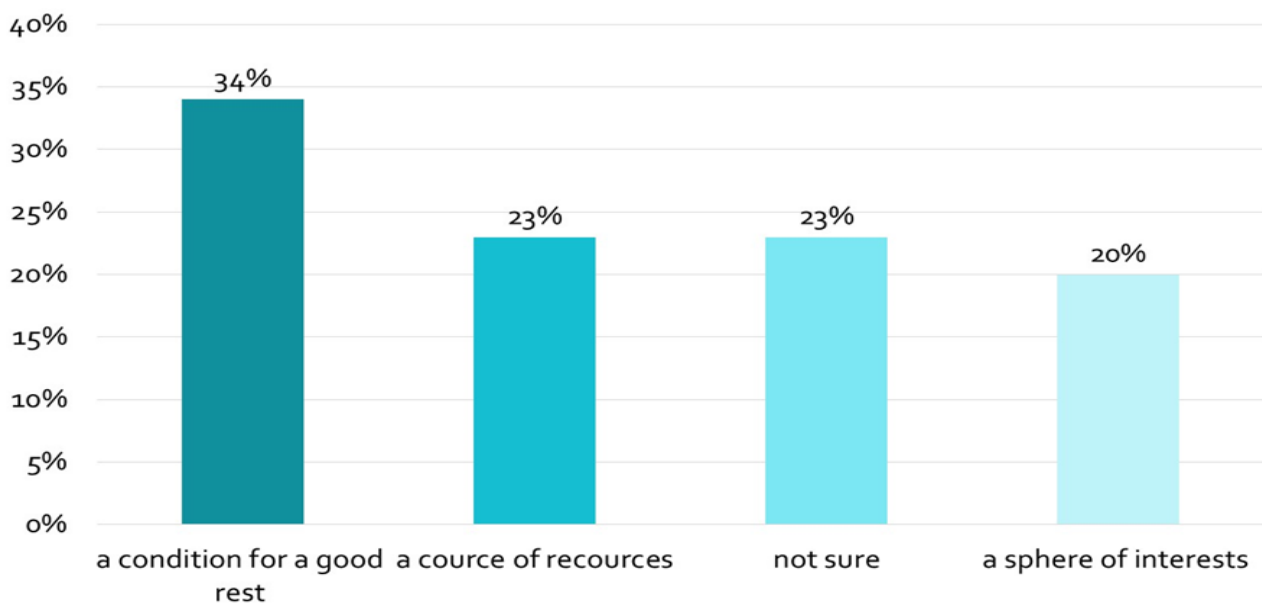

Fig. 9. The scheme of the division of the answers of the respondents to question "What is nature for you?"

We also examined questions about whether respondents have information about conscious consumption, as well as questions about their knowledge of environmental regulations. Thus, we determined that the respondents have a low level of knowledge about conscious consumption, as well as a low level of knowledge about environmental regulations. They were asked about their knowledge of the standard documentation in the environmental sphere. It is worth mentioning that Federal Law. "On the protection of the natural environment " has become the best known one, and the least known is " The principles of sustainable development". It should be noted that $36 \%$ of the respondents have no information about the documents listed below. A detailed chart is presented in Figure 10 (the data is presented as the member of respondents).

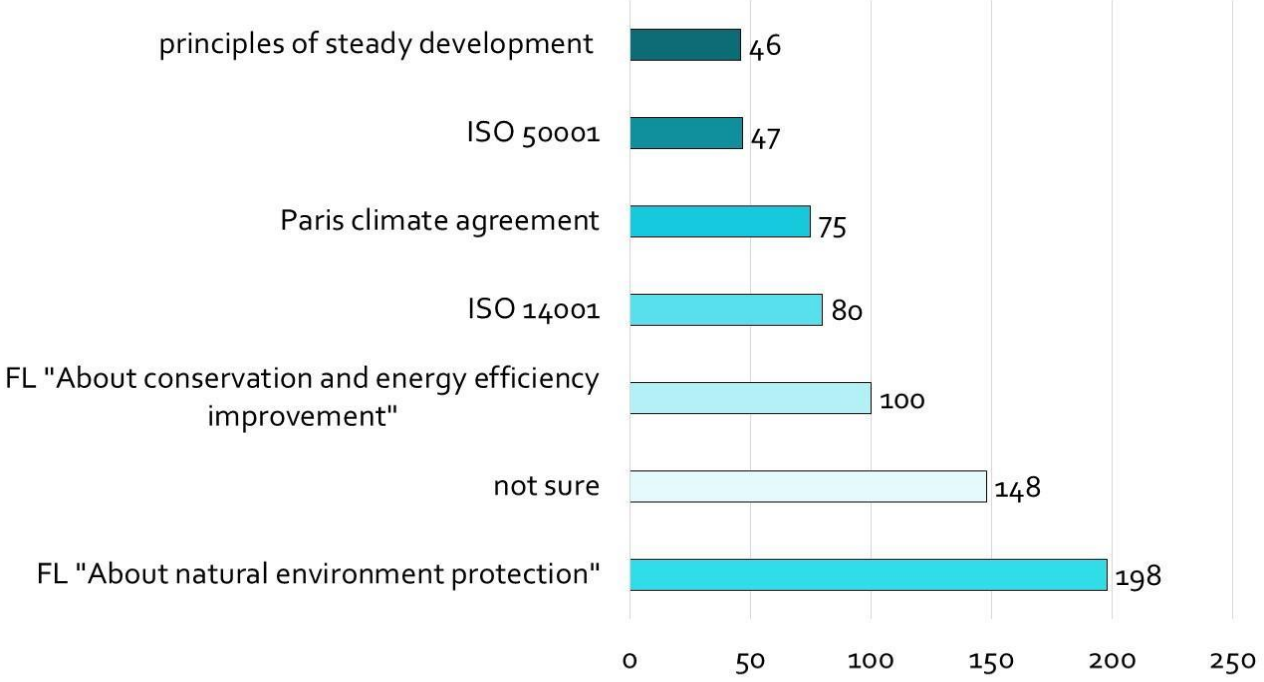

Fig 10. The scheme of the division of the respondents" answers to question "What of the mentioned down below documents in the eco-logical sphere are you familiar with?"

To summarize, according to the data obtained, we have identified several problems presented below:

1. Consumer attitudes toward nature and resources 
2. Low level of the knowledge base about conscious consumption

3. Ignorance of primary regulatory documents in the environmental sphere

These problems are caused by insufficient development of three components that form the environmental culture of a person:

1. Environmental awareness

2. Environmental education

3. Environmental behavior

Using these components, authors have developed practical and theoretical solutions to the problems mentioned earlier in our paper, which can be complemented by various researches.

\section{Theoretical and practical solutions to environmental culture problems of students}

Environmental culture is a result of continuous development of vrs external and internal factors that influence the development of views, dogmas, actions of a person oriented on the environmental preservation; according to Likhachov, the essence of environmental culture shall be studied as an organic unity of environmentally developed consciousness, emotional and psychological conditions, and science-based utilitarian practical activities [9]. Now we can add environmental education to that list. Environmental education promotes the organization of initial knowledge about the environment and environmental problems. Environmental education is organized as environmentalization of the consequences of the educational process and their implementation in the educational process. It is worth noting that three initial factors, i.e., environmental consciousness, education, and behavior form only primary environmental culture, which later keeps developing endogenously. Each problem was examined in a separate subchapter for a detailed study. Each subchapter used theoretical and practical methods to the solution of these problems.

\subsection{Consumer attitude to nature and resources}

Consumer attitude to nature and resources appears because of the low level of environmental consciousness, which is composed of people, ideas, dogmas, stereotypes, and other spiritual formations that reflect and regulate relations between man and nature [10]. The development of environmental consciousness is characterized by attributes such as globality, a reinterpretation of essential issues of a worldview based on science, the connection between science and humanitarian values, and the desire to act for the preservation of nature [11]. Thus, the organization of environmental consciousness is a complex process that impacts the inner world of man using reinterpretation of existing ideas based on human anthropocentrism. For a gradual organization of environmental consciousness of a student, it is necessary to "green" the process which will work in the context with purposes of sustainable development. For reinterpretation of worldview matters by student, it is necessary to use a system of cases focused on involving students in students to the "greening" processes, i.e., to show them that they can contribute to the development and preservation of the environment.

"ECO-days» are widely used by foreign organizations to obtain or accumulate basic knowledge about the environment, as well as human impact on the environment. These are days when people give up industrial welfare, expressing their solidarity for the preservation of the environment. They conduct eco-campaigns to save resources and free goods, animal days are also included in the list of "ECO-days". Such major campaigns not only provide necessary information about the environmental situation but also involve people in the 
process of greening their lives. To this end, holding environmental days on campus allows students to get the necessary information about environmental problems and ways to solve them, take part in environmental campaigns and contribute to the greening of education.

As part of "ECO-days," the opportunity to hold an environmental campaign "A day without plastic" helps the student understand that it is possible to spend a day without using plastic. This structure shows the campaign participants that giving up plastic products is not a difficult and painful process that requires a lot of human effort. By engaging in the process of rejecting plastic products, the student organizes a consciousness focused on preserving the environment from "plastic waste", which suffers from an overabundance of plastic on its surface. Such environmental campaigns organize not only human environmental consciousness, but also the environmental conservation-oriented behaviour. Campaigners can share their victories on social media, which will also increase other students' interest in environmental issues and solutions. Returnable goods that can replace conventional ones can serve as motivation in these campaigns.

The next stage of the organization of environmental consciousness can be landscaping the territory of the university, which will have a good impact not only on the external environment of the university but also on the student's consciousness. When planting greenery students begin to understand that everyone can contribute to the preservation of the environment. Environmental awareness is part of the environmental culture which determines the understanding by people of their impact on the environment and their responsibility for its preservation.

\subsection{Low level of the knowledge base on conscious consumption}

Conscious consumption is also called ethical. It is minimizing the human ecological footprint. It is based on five principles that are organized along the lines of no single-use goods, reduced consumption, reuse, recycling and waste management. The very word "conscious" impels rational human consumption of resources and goods, as well as behavior oriented towards the conservation of those resources. Gaps in conscious consumption arise from a lack of environmental behavior. It is the environmental behavior that develops resource conservation in humans. In order to develop the environmental behavior in humans, it is necessary to use the required media space, which currently is the main factor in the organization of human thinking and behavior.

Technology and social media are becoming an integral part of our daily lives, and it is easier for a person to find information on search engines than to look for it in a library. The social and public space has made it possible to obtain information and knowledge that would be difficult to access in normal life. This has served the fast development of the media space which cannot exist without social media. Also, the social space has grown into the 21 st century generation, often referred to as the digital generation. This generation has changed the way we work with received information, based on visual resources with brief text detailing [12]. For the modern generation, the visual component plays a significant role in expressing their demands and feelings, man has been using communication through images and colors since ancient times, when paintings told about the life and livelihood of the first people, and therefore it is easier for man to perceive information through images and Figures. Nowadays, the presentation of brief information is called animated graphics and is widely used in communication. The role of animated graphics in organizing environmental behavior is evident because it is the visual information that is accepted by humans faster than any other type of information. Animated graphics are composed of graphical information presented as visual graphics, data, and knowledge oriented to show complex information quickly and accurately [13]. That is why the use of the eco-animation for the development of environmental behavior is considered the most effective, and its 
placement in the territory of universities will contribute to a faster and more understandable acquisition of environmental information.

The next method that stimulates environmental behavior is also social space, i.e., social media. According to (Digital 2020), in January 2020, the population of social networks was 3,80 billion people. In Russia, the figure was 70 million people. Also, the time spent on the Internet is 6 hours and 43 minutes per day. Of this time, a person spends 2 hours and 24 minutes a day on social networks. According to the above data, it is impossible not to evaluate the role of social space in human behavior and action. To a great extent, it is the social networks that have the upper hand in human behavior and attitudes to various situations.

That is why the use of social networks in the organization of environmental behavior will be an effective method of impact, i.e., the publication of articles on conscious consumption in social groups of the university and the involvement of human resources in this process. Thus, students will receive the information from a "reputed" source and use the information obtained in everyday life, which will allow developing environmental human behavior.

\subsection{Ignorance of regulatory documents in the environmental sphere}

The next problem of the development of environmental culture is insufficient knowledge of the casic regulatory documents in the environmental sphere. The reason for this is the low level of environmental education or the absence of it. The emergence of this problem can be explained by the fact that it is quintessentially young and just beginning to be created. Nonetheless, the work of the future professional and decisions they will make depend on the level of knowledge of rules and regulations. The condition in the environment where one works depends on the environmental orientation of the decisions made. The students who are future professionals must know their environmental rights and obligations, factors such as the environment and the company's image will depend on it. Thus, the development of this factor is an integral part of environmental culture education. Motivation for environmental rules and regulations can be the actions described below.

Conferences with the invitation of environmental specialists from enterprises can promote the study of the impact of various professions on the environmental conditions, as well as ways to prevent environmental problems using modern methods in the industry. Students' professional skills with presentations will help to study the existing rules and regulations in the environmental sphere particularly and also methods of their use.

The pedagogical staff has a significant role in the organization of environmental education. It immediately shapes the attitudes toward the environment and motivates the students. It is the motivation that is the key to the student's interest. It stimulates the study of the topic. That is why the process of "greening" the education system should start with greening of the thinking of the pedagogical staff.

Game education is widely used for informal education and organization of thinking. Significant advantages explain the high efficiency of game-based learning methods in comparison with traditional methods. Some of them are especially noteworthy: visibility of the decisions made, uneven time scale, acceleration or deceleration of the sequence of events, repetition of experience with changing of goals. An important role is played by the information support of training games. I Informational provision includes a list of components:

1. Description of the situation which is the basis of the game training

2. Regulations and criteria for evaluating results; documents of planning and organization of game training

3. Regulatory and reference documents. 
The game situation forms the basis of the game training program and, as a rule, includes its detailed description. A detailed description can be provided before the beginning of the game and supplemented (specified) in the process of the game [14]. Conducting quests on the use of the rules and regulations in the environmental sphere has a positive impact on the organization of environmental education. Thus, the students will learn the rules and regulations in the environmental sphere more thoroughly.

The above methods can be supplemented and used in the development of environmental culture of students, and can be changed depending on the level of the student ecocentrism.

\section{Discussion}

Early studies of students' environmental culture were conducted as recommendations for its development and considered only in narrow areas or considered as a whole but without referring to students. The main focus was on society as a whole [15], or business processes [16]. Some research pointed to the need of developing students' environmental culture based on their assumptions and experience. Studies aimed at identifying the main problems that hinder the development of environmental culture of students of technical universities have not been considered. Also, student's own desire for the development of environmental culture has never been broadly studied. A similar survey of environmental culture of college students through a questionnaire was presented in the article [17], but due to the small number of respondents and the use of random sampling, it did not allow us to obtain extensive data. Nevertheless, this study shows the expected level of development of environmental culture of students of a pedagogical college.

This paper also considers the effectiveness of measures for the development of the environmental culture of students. The study of environmental consciousness and culture in general was considered in the article [18] dealing with the problems of the development of environmental consciousness in modern society and obstacles to the "greening" of human thinking. Based on the materials studied, it became clear that a purposeful study of the state of environmental culture of students has not been carried out. Therefore, it was decided to pay attention to this group of people, since they are the most open to learning new things. Besides, in the process of learning, the greening of thinking can be more effective than in other cases. The development of environmental culture at the university is necessary for training specialists who are ready to make environmentally-oriented decisions and preserve the environment. That is why students, future professionals, have become the object of this study. In the course of the study, the results were obtained on the environmental responsibility of students, their attitude to nature, and the main environmental problems. Students' environmental knowledge and their readiness to develop an ecological culture at the university were also considered. Figure 11 shows the distribution of answers among respondents to the question "Do you think it is necessary to develop environmental culture among students?" 


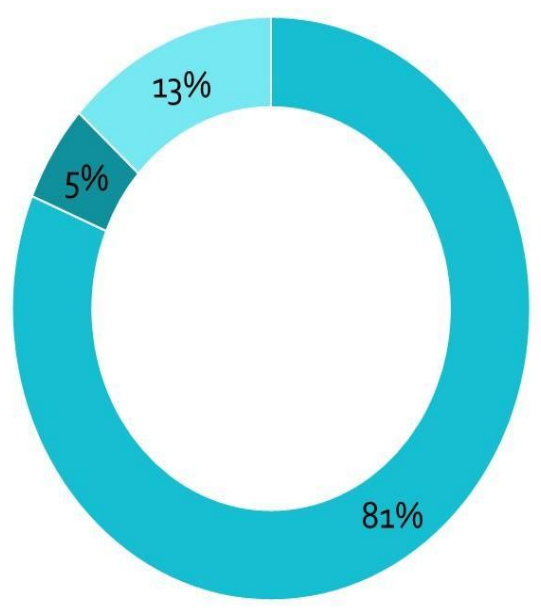

yes no not sure

Fig 11. The diagram of the division of the respondents' answers to the question "Do you think it is necessary to develop an environmental culture among students?"

As can be seen from the diagram, many respondents gave a positive answer to this question, which indicates that students understand the need to develop environmental culture.

Some regularities were also obtained regarding the development of students' environmental culture. For example, female respondents are more willing to participate in environmental and political activities; this is concluded based on the majority of "Yes" responses. It was also reported that the ability to take responsibility for the environmental state of the region of residence decreases with age, both for male and female respondents. Another pattern was established regarding environmental engagement. In men, however, the desire to give up material possessions to preserve nature diminishes as they age. This was determined from the answers to the question of whether they can give up material goods for nature conservation: the proportion of "Yes" answers gradually decreased. The data presented in the study help to better understand the current state of environmental culture of students of technical universities in Russia, specifically, on the territory of the Tyumen Region, since most of the respondents were students of Tyumen universities. The study for the first time examined students' attitudes to the development of environmental culture and their desires. It considered not only the specific level of environmental culture but also their knowledge in the field of environmental regulations and students' attitude to making environmentally-oriented decisions of their own. By disaggregating the results by gender, the influence of gender on environmental responsibility and behavior was examined. The age of the respondents also played a noticeable role in shaping the environmental culture of students. This study provides extensive information about the level of the development of environmental culture of students of Russian universities, which may serve as the first impetus for further studying of this issue.

The main limitation of this study is the method of random sampling of students and limited responses to questions, and this study does not provide specific answers to the question of the development of environmental culture of students. This is due to the fact that the development of environmental culture depends on many cultural, social, economic, and political factors. These factors cannot be fully studied, as they are too large. The 
presented methods of developing students' environmental culture are theoretical and cannot guarantee perfect results. Therefore, this study shows the need for more in-depth study of this issue and further direct work to pay closer attention. It is worth noting that the interview method facilitated a detailed study of the students' opinions and obtaining the best results. The sampling of students had to be made taking into account the specialization of students.

\section{Conclusion}

Personal motivation and intrinsic motives play a significant role in the organization of human environmental culture. To study this matter, respondents were also asked whether they were willing to study environmental problems in the process of learning and to develop environmental culture in themselves. The answers showed that many students were willing to study environmental sciences and to cultivate an environmentally oriented person with the environmental worldview. More than $75 \%$ of the respondents answered this question in the affirmative, which indicates a positive dynamic in further study of this topic.

With this purpose, the theme of the further studying will be an increase in the level of environmental culture of students with the use of all above-stated practical and theoretical methods, i.e., study of development of environmental culture and its level after application of these methods. Sample methods can be supplemented and progress during the repeated studies and some components can be changed.

The development of environmental culture, as it was mentioned above, depends on many external and internal factors, which impact man. Of course, one of the factors is the family and society where the man lives. It is the family that gives us initial knowledge about nature, and society organizes our behavior and worldviews. Of course, under the conditions of globalization, we receive most of the information from the social space, i.e., the social space can be considered as the third primary sphere of man's formation and thinking. The following outer factors influence the organization of environmental culture in man: the visual component, the public opinion, the information received from media space, impact of the authority of other members of society, outer motivation; also, such internal factors as the worldview, personal motives, knowledge, experience, consciousness, and various needs.

Of course, man, as a rational being, must understand his responsibility for the preservation of the environment and its prosperity. It is man's practical understanding of his impact on nature that helps to escape environmental disasters and other problems related to the environment. That is why the development of environmental culture at this stage of social development is absolutely necessary because nature took the backseat and is accepted as an object of human manipulation.

Man originally saw himself as part of nature and cared for it; humans evolved along with nature and identified with it. A deep understanding of preservation will help to avoid future environmental disasters, and the education of an environmentalist will allow them to work in the context of sustainable development. It is necessary to educate a specialist in such qualities as the specialist as practical readiness, responsible attitude to the environment, the ability to use one's environmental knowledge, ideas, and professional skills. Such a specialist will be able not only to preserve the environment, but also raise the image of the enterprise he/she works.

The necessary conclusions of the article are that it is worth organizing environmental education gradually, without sudden leaps; environmental culture is a major factor in the organization and development of humanity; environmental culture is a set of complex endoand exogenous factors; students being the future professionals who will come into contact with the environment should generate ethical environmental culture in them. 
In conclusion, it is worth noting that the development of environmental culture is a global rethinking by man of his principles, built on anthropocentrism, as well as a change in the way of life and attitudes that have developed in society. Man must understand the future of the planet, and whether or not to change himself depends on his decision.

\section{References}

1. J.J. García-Machado,M. Martínez-Ávila Environmental Performance and Green Culture: The Mediating Effect of Green Innovation. An Application to the Automotive Industry Sustainability, (2019)

2. A.G. KoryakovManagement of sustainable development of an industrial enterprise: theory, methodology, practice,(Moscow,2012)

3. S. Elhedhli, R. Merrick Green supply chain network design to reduce carbon emissions.Transportation Research Part D: Transport and Environment, 370379(2012)

4. F. Ramírez, J. Santana Environmental Education and Ecotourism,(Cham. Springer,2018)

5. I.Altman, A.Rapoport, J. F. WohlwillHuman Behavior and Environment.ADVANCES IN THEORY AND RESEARCH,(New York: PlenumPress, 1980)

6. R. Linton Acculturation in Seven American Indian Tribes,466(Peter Smith Pub Inc., 1963)

7. A.V. Gagarin Professional and ecological culture of the future specialist: features of its manifestation and development in the conditions of eco-oriented activity. Acmeology,28-33 (2010)

8. A. I. Fokin Ecology The environmentally-Ooriented worldview of the an individual and the prolem of its formation in psychology, pedagogy, and acmeology. Acmeology,81-87 (2010)

9. B. T. LikhachevPhilosophy of education,(Moscow. Prometheus,1995)

10. A. R. Ashkhamaf Ecological consciousness: on the problem of definition of the concept. Bulletinof the Adygeya state University. Series 1: regional Studies: philosophy, history, sociology, law, politcal science, cultural studies, 15-18 (2010)

11. I. N. Simonova,O. V. Vernikova Ecological culture as a phenomenon of modern higher tecnical education. Modern problems of science and education,1, (2015)

12. R. Ghode Infographics in news presentation: A study of its effective use in Times of India. Jounal of Business Management \& Social Sciences Research,35-43 (2012)

13. D.Newsom, J.HaynesPublic relations writing: Form form\& style,(Belmont, CA :Wadsworth Publishing,2004)

14. Vasilenko V.G. 2014. Game methods of conducting training sessions in higher education.Bulletinofthe RMAT. pp. 84-94.

15. B.Tonn, M. English, Ch. Travis A Framework for Under-standing and Improving Enviromental Decision Making. Journal of Environmental Planning and Management,43(2), 163-183 (2000)

16. G. M. Perron,R. P. Cote',J. F. Duffy Improving environmental awareness training in busness. Journal of Cleaner Production, 14, 551-562 (2006)

17. I. V. Rudenko,K. A. Naumavichute Formation of ecological culture of pedagogical College students. Baltic humanitarian magazine,7(1(22)), 273-275 (2018) 
18. N. V. Ulyanova Ecological consciousness and ecological culture, problems and prospects. Buletin of Tomsk state pedagogical University,6, 57-61 (2007) 